\title{
Hispa-NICE: A Pipe Dream or a Realistic and Necessary Initiative?
}

\author{
Fernando Antoñanzas ${ }^{1}[$
}

Accepted: 26 March 2021 / Published online: 23 April 2021

(c) The Author(s), under exclusive licence to Springer Nature Switzerland AG 2021

In December 2020, a group of 300 professionals and experts on the Spanish health care system signed a manifesto [1] advocating for the creation of an independent authority for the evaluation of health practices and policies, a kind of Hispa-NICE, to promote that price and reimbursement (P\&R) decisions are systematically based on efficiency criteria.

In this editorial, we will overview the structure of the Spanish P\&R process, remark on some of its pitfalls, and highlight some of the challenges of this new body that is promoted by the manifesto.

\section{A Briefing of the Price and Reimbursement Process}

The $P \& R$ regulation has remained rather stable for the last 3 decades. It has been based on several criteria, initially established by the 1990 Spanish Medicines Act (updated in 2006 and 2015) [2-4]. These criteria mainly referred to incremental efficacy, safety, severity of the disease, therapeutic alternatives and economic considerations (e.g. section $\mathrm{C}$ of article 92 states: "the social and therapeutic value of the drug and its clinical benefit taking into account its cost-effectiveness relationship"; and section D states "rationalization of public expenditure for drugs and the budget impact for the National Health System"). In practice, it is also common to look at the prices in other neighbouring countries of the EU. However, health authorities have not yet implemented a formal mechanism to cope with the cost-effectiveness mandate. Nevertheless, some pharmaceutical companies voluntarily include cost-effectiveness analysis in the dossiers they submit for the approval of new products, expecting the results to be considered during the $P \& R$ process.

Fernando Antoñanzas

fernando.antonanzas@unirioja.es

1 Department of Economics, University of La Rioja, 26004 Logrono, Spain
Although Spain is a decentralized country with 17 regional health care systems, the $\mathrm{P} \& \mathrm{R}$ decision process is still centralized and is mainly carried out by the Ministry of Health and the Interministry Commission of Drug Prices and Health Products, who decide whether a new approved product is publicly funded and the maximum authorised price. Products dispensed by community pharmacies have a uniform price nationwide; however, price negotiations are common for drugs dispensed in hospitals and frequently adopt the form of confidential discounts.

The Spanish Agency of Drugs and Medical Devices was created in 1997 with the initial objectives of authorising the marketing of new products, review of the existing products, and assessment of drugs authorised by the European Medicines Agency, among others. Progressively, this agency started to publish reports on new health products that included the target population, their positioning, and assessment of their incremental efficacy and safety, all of which are valuable inputs for the $P \& R$ process. When the report states that there are uncertainties regarding any of these items, the manufacturer's negotiating power regarding the initial requested price may be reduced during the $P \& R$ decision.

Interestingly, in spite of Spain being traditionally classified as a budget-oriented country, some of the key parameters that summarize the Spanish P\&R process, such as the average time needed for marketing authorisation, the number of new products that are finally approved, and their price levels, are aligned to those of other Western EU countries, independently of their use of the cost-effectiveness criterion.

The decentralization of Spain has made possible the creation of seven regional Health Technology Assessment (HTA) agencies in the last 40 years. Generally, these agencies evaluate new technologies, mostly devices, medical procedures and health projects, and share their findings among themselves as well as among other EU agencies, in addition to publishing some of their reports. These assessment reports are useful for managing some new pharmaceutical products and technologies in general, and to influence medical protocols, formulary inclusion and prescription guidelines. However, P\&R decisions are currently being adopted in the absence of these 
reports, which occur later in the process when health care is managed by regional health authorities.

Furthermore, each region has its own General Director of Pharmacy, or similar body that analyses new drugs and advises on how they should be prescribed. This analysis commonly refers to drugs dispensed at community pharmacies. Incremental efficacy and safety are the major drivers, together with price, which is scrutinized when several options are available. Some regions go beyond this and perform economic evaluation studies for some drugs or review other existing drugs; however, this is not a routine activity. Drugs dispensed by hospital pharmacies (for instance, most of the oncology drugs) follow a more complex process. Every hospital has its own pharmatherapeutic commission that performs a second assessment of the drug (in addition to the national assessment), incorporating new inputs as the maximum price authorised by the central government, and other evidence. Some regions carry out this second assessment and communicate the results to their hospitals. GENESIS, the professional association of hospital pharmacists, frequently volunteers to perform appraisals of new products and also incorporates the results of economic evaluations that international or national agencies may have published (sometimes these analyses are performed by the GENESIS group). In order to better control drug budgets, hospitals (namely, hospital pharmacies) are allowed to negotiate discounts and other types of financial agreements with manufacturers. Information on the efficiency of new products becomes an important managerial tool in these negotiations.

Last but not least, the Advisory Committee for Funding Drugs of the National Health System, a body created after updating the 2006 Drugs Act [3], started to develop its activities 2 years ago. The mandate for this committee is to advise on how economic evaluation can be applied to the P\&R of drugs adopted by the Ministry of Health, as well as to advise on new policies to increase the sustainability and efficiency of the public reimbursement of drugs.

In summary, it is common to see several assessments for some health products and information gaps for others. The existence of several regional HTA agencies, together with the general directions of pharmacies and commissions at the hospital level, contributes to the generation of different types and layers of information. Although for an external observer this picture may produce confusion and distress, the system seems to manage all these issues in an acceptable timeframe, as the penetration pace of new products into the Spanish market is comparable with that for other countries [5].

\section{Hispa-NICE as a Challenging Solution}

Nonetheless, things may still improve. The development of new complex drugs, with rocketing price requests, increases pressure on already tight health care budgets. The existing analytical instruments and the administrative organization for the appraisal of drugs seem to be insufficient to fix prices according to health value. The aforementioned manifesto pushes forward the creation of a new regulatory body that would establish the cost-effectiveness criterion as the cornerstone of the new $\mathrm{P} \& \mathrm{R}$ process.

Nevertheless, this aspiration is rather abstract and needs to be more specific. Importing institutions from one country to another is not straightforward. They do not always travel well across jurisdictions, and historical and organizational factors can heavily condition the final desired result. The National Institute for Health and Care Excellence (NICE) has done a good job in integrating separate elements of information needed for $\mathrm{P} \& \mathrm{R}$ decisions, as well as appraising many health technologies and clinical processes to improve health care management. However, in a decentralized health care system with many bodies managing drugs, this new institute does not only need to be 'copied and pasted' but also integrated into a complex regulatory regionalized system. The risk of ending up with multiple regional NICEs is high in a country where several regions are proud of having a particular version of any national body, no matter what the costs are for duplicating central government institutions to a regional level (in fact, this also seems to be applicable to the UK too, where, a few years after the creation of NICE, the Scottish Medicines Consortium, a kind of 'MacNICE' as someone funnily named it, started to work with the purpose of "providing a single point of advice, reducing duplication of work and differences in availability of medicines across NHS Scotland" [6], but overlapping some NICE activities).

Hence, the already mentioned manifesto implicitly referred to the idealistic, and likely naive, aspiration of supporting the creation of a central institute in charge of some of the functions carried out by the Spanish Agency of Drugs and Medical Devices, plus some of the assessment activities performed by regional HTA agencies, General Directors of Pharmacy, hospital committees, and the new Advisory Committee of the Ministry of Health. The activities of this ideal institute, mirroring NICE, would hopefully integrate tasks, already developed by both central and regional governments, and include the economic analysis of drugs in a more systematic and influential way for the P\&R process. However, unless all these functions are well-designed and the regions accept the new institute and are aligned to this initiative, the efficiency of the final assessment process may be uncertain as the country may again witness a new layer in the already complex $\mathrm{P} \& \mathrm{R}$ process. 


\section{References}

1. Manifesto advocating for the creation of an independent authority for health practices and policies. Available at: https://www.diari ofarma.com/2020/12/13/trecientos-expertos-reclaman-la-inmed iata-creacion-del-hispanice. Accessed 9 Mar 2021.

2. Spanish Medicines Act (Law 25/1990, of December the 20th). Available at: https://www.boe.es/eli/es/1/1990/12/20/25. Accessed 9 Mar 2021

3. Law of Guarantees and rational use of drugs and health products (Law 29/2006 of July the 26th). Available at: https://www.boe.es/ eli/es/1/2006/07/26/29/con. Accessed 9 Mar 2021.
4. Legislative Royal Decree $1 / 2015$ of 24th of July, that approves the reviewed text of the Law of Guarantees and rational use of drugs and medical products. Available at: https://www.boe.es/eli/es/rdlg/ 2015/07/24/1/con. Accessed 9 Mar 2021.

5. IQVIA. EFPIA Patients Waiting to Access Innovative Therapies. Indicator 2019, Survey. May 2020. Available at: https:// www.efpia.eu/media/554526/patients-wait-indicator-2019.pdf. Accessed 17 Mar 2021.

6. Scottish Medicines Consortium. Available at: https://www.scott ishmedicines.org.uk/about-us/. Accessed 9 Mar 2021. 